from the earth, and without a single supporting guy, this chimney, because of its relatively narrow base, presents a very striking appearance.

The concrete foundation of the chimney is $36 \frac{1}{2}$ feet square and 6 feet thick. For the chimney proper, the mixture was one part cement and three parts sand.

The chimney is constructed in two parts. From the foundation up to a height of 90 feet there are two distinct shellsone built within the other; while for the rest of its height it is built with a single shell.

The purpose of the double shell is to protect the structure from cracks and strain due to extreme variations of temperature. The inner shell, which is separated from the outer one by an air space of five inches, is designed to shield the outer shell from the direct effect of the intense heat at the base of the chimney; while the outer serves as a like protection to the inner shell, by shielding it from cold weath-

er, which might cause it to crack by cooling too suddenly.

The outer shell also takes up the heavy bending stresses caused by wind pressure. Not only are or dinary conditions guarded against, but the chimney is expected to withstand a tornado. Circulation of air between the shells is secured by the provision of small openings at the bottom.

The entire chimney was built in three-foot sections, and an average of three feet a day was made in the construction of the double sec tion, and six feet per day on the single or uppe single or upper section. Sectiona molds were used, and the entire
work was handled work was handled from the inside, a scaffolding being built up with the chimney. All materials were rais. ed by means of a cable attached to the drum of the engine that operated the concrete mixer.

The inside diameter of the $\mathrm{ch}$ imney is 18 feet, and the outside 21 feet. From base to apex the chimney is reinforced with $\mathrm{T}$ iron according to the Weber system.

The bridge built by J. W. Murphy in 1863 , over the Lehigh River at Mauch Chunk, for the Lehigh Valley Railroad, was the first pin-connected bridge constructed entirely of wrought iron in its main mem-

bers; cast iron being used only for joint boxes connecting the compression members. Many bridges of similar construction were built after this, but it was not until after the failure of the Ashtabula Bridge, in 1876, that cast iron was entirely discarded as too unreliable a material to be used in any parts of a railroad bridge. plane must be cleared, either by study of the past efforts of others, or by personal experiments: The supmovement in it, the extent in square feet of the sup-

\section{A NEW AEROPLANE.}

The following points in flying by means of the aero. porting power of the air, the resistance to a forward

it is obvious that there is the margin between 10 pounds and 200 pounds to carry the weight of the aviator and the flying machine. Care and attention machine, with the object of obtaining automatic equibrium and safe support.

After numerous experiments with models, many of them on different lines from any previously c o n structed, and many of them many of them
very and encouraging, I have begun and nearly completed the construction of a full-size flying machine. It is built on the aeroplane principle, that is, it has no gasbag or balloon to support it, but is supported in air only when in motion, and by the upward reaction of the air upon the underside of thin fixed surfaces or aeroplanes, which are slightly inclined to the line of motion.

The framework is of light bamboo, of one and one-quarter inches, and is covered with light canvas porting surface, the form of the flying machine, the material of which it is to be built, the power of the motor to be employed, whether propellers or moving wings are to be used, the form of rudders or other expedients for effecting the steering and starting, the maintenance of the equilibrium, and the plan of safely alighting.

The supporting power of the air has been determined. Prof. S. P. Langley, of the Smithsonian Institution Washington, D. C., sustained under favorable condi.

The upper forward aeroplane is a trapezoid in shape. Its forward edge is 13 feet in length, its rear edge is 18 feet. Its sides are 7 feet 3 inches in length, and it has a depth of $61 / 2$ feet. The midale front aeroplane forms a diedral angle with the top of its sides reaching the upper aeroplane, and its two halves are $71 / 2$ feet long, with a depth of $6 \frac{1}{2}$ feet. The lower front aeroplane is rectangular in shape, and has a width of 10 feet and a depth of $61 / 2$ feet. The open space dividing the two sets of aeroplanes is 6 feet wide.

The upper rear aeroplane is rectangular in shape, and 21 feet by $61 / 2$ feet in width and depth. The two halves of the middle or diedral angle rear aeroplane are each 11 feet wide by $61 / 2$ feet in depth. The low er rear aeroplane is rectangular in A NEW AEROPLANE.

tions by aeroplane a maximum of 200 pounds per horse-power expended. This result was reached by placing the aeroplanes at the end of a long arm re volving about a fixed center. Hiram Maxim, Mr. Har grave, and others have constructed motors weighing less than 10 pounds for each horse-power developed. Propulsion and lifting power are solved problems, and shape, and 9 feet by $61 / 2$ feet in width and depth. There is a total of $5561 / 4$ square feet of surface; but as the supporting surface of the diedral angle aeroplane is not greater than the horizontal projection of such diedral angle aeroplane, the supporting surface is calculated at $4911 / 4$ square feet. These diedral angle aeroplanes give direction to the line of flight, prevent 
oscillation, and overcome a tendency of the machin to turn around on its center of gravity. They also give lateral stability; for when the machine tilts, th halves of the diedral angle of the aeroplanes which are down are more horizontal than those on the other side, and receive consequently greater air pressure, and the equilibrium of the flying machine is recovered.

Longitudinal equilibrium is gained by dividing the air current that passes the under surface of the aeroplanes. It is apparent that any upward or downward tendency of either the fore or aft aeroplanes is counterbalanced by the opposite effects on the other planes The light connecting rod crossing the open space between the fore and aft aeroplanes forms the fulcrum upon which this force of the wind acts.

The inclosed triangular chamber formed by the diedral angles of the middle aeroplane with the upper aeroplanes gives direction to the air current passing through them, and imparts additional steadiness to the
flying machine. The edges of the diedral angle aeroplanes not extending to the edges of the two upper aeroplanes, a further improvement in the stability is gained by leaving the same yielding and elastic under pressure.

The position of the aviator, as that of the motor, is below the aeroplanes. This brings the center of gravit below the center of pressure. By a simple arrangement of levers in connection with the lower front aeroplane, which also is a rudder acting horizontally, automatic equilibrium is imparted to the flying machine by the shifting of the position of the aviator caused by the tilting of the flying machine upward or downward. This pendulum motion of shifting the cente of gravity with reference to the center of pressure can be enlarge at will, and made to correspond to the change in the center of pressure produced by the alter ation in the angle of incidence or by greater speed, and assists the efforts of the horizontal rudder to correct assists the efforts of the horizontal rudder

The machine is mounted on four wheels, the two front ones being capable of guidance. This arrangement permits alighting at an acute angle and rolling upon the ground until momentum is exhausted; or to gain headway by

My weight is 167 pounds. The weight of the flying My weight is 167 pounds. The weight of the flying
machine without the motor is 165 pounds. The motor machine without the motor is 165 pounds. The motor 307 pounds, or 1.6 square feet of surface for each pound of weight to be lifted. That this proportion of square feet of surface to pounds in weight is most deand man-lifting kites.

Examples of this sort in nature are not very conclusive. The dragon-fly and the gnat, if their propor tions were magnified until each weighed a pound, would have 25 and 50 square feet of surface respectively. The condor, the largest soaring bird, weighs 17 pounds and has less than 10 square feet of supporting area. The ratio of the wing surface of the swallow to its weight is about $3 \frac{112}{2}$ to 1 . The giant petre (Procellaria gigantea) a wonderful example of longsustaine flight, with at times absolutely motionless wings, has a ratio of 1.56 square feet of surface to each pound of weight, and is supposed to expend less than $5 / 100$ of a horse-power of effort to keep itself afloat in the air.

At an angle of flight of ten degrees, the air reaction, according to the table compiled by Prof. S. P. Langley, from the result of exhaustive experiments, in which experiments he was aided by an appropriation from the United States government, is 30 per cent of angle of 90 egrees,

At a velocity of 30 miles an hour, or 2,640 feet per minute, the wind, according to Smeaton's formula, exerts a pressure on a plane at right angles to the current of 4.5 pounds to each square foot of surface. The supporting power of the flying machine running at 30 miles an hour will therefore be $4911 / 4$ times 4.5 time 0.30 , or 662.85 pounds sustained. Inasmuch as the total weight to be lifted is less than half that figure wings, braces or other resistance will require that large margin of resistance, it is likely that a less spee or a smaller angle of incidence to horizontal progression will be sufficient

There are two propellers of four blades each, 8 feet in diameter, and varying in width from 5 inches to 18 inches at the extreme edge. The skeleton structure of the propellers is of bamboo, and is covere with light oil canvas. The blades are in pairs, one behind the oil canvas. The blades are in pairs, one behind the
other, and connected together with diagonal struts and ties, so that in motion the members of one blade will be in compression and the other in tension.

While I have made application for letters patent for various parts of my flying machine, I have no desire to precluaie anyone else experimenting along the same lines, and it is because I believe for the general advancement of the science that one should communicate vancement of the science that one should communicate
results with others who may be interested in the same field, that I make public these experiments. It wil be pleasant to record success at the trial, but progress in this science has so far been built upon failures. If, however, the flying machine should not fly, it will be no reason why this research should be abandoned, for success is often built on failures.

\section{THE TEMPLE OF ABU SIMBEL}

The forgotten and half-obliterated civilization of ancient Egypt has given us few more splendid evidences of its departed magnificence than the ruins of the sanctuaries at Abu Simbel. These are counted among the most stupendous monuments of early Egyptian architecture, and even the gigantic edifices found in Egypt proper are hardly more interesting. Abu Simbel is located on the west bank of the Nile, between Korosko and Wady Halfa, in Nubia. The illustration herewith is of the entrance to the so-called Great Temple, which was dedicated primarily to the gods

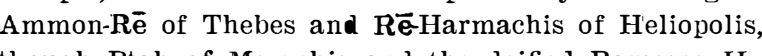
though Ptah of Memphis and the deified Rameses II., who founded it nearly thirteen centuries before Christ, were also worshiped by its votaries. Burckhardt, in 1812, first called the attention of Egyptologists to this sanctuary. In subsequent years Belzoni, Lepsius, and Mariette repeatedly freed the temple from the sands of the shifting west desert and laid bare the wonders of the inner chambers. In 1892 Capt. Johnstone, R.E., restore the façade and built two walls to protect the temple from the encroaching sands.

The longer axis of the Great Temple runs almost due east and west, with the entrance at the eastern extremity, so that the rays of the rising sun penetrate even to the innermost sanctuary. The length of the rock-temple, hewn out of the living granite of the hillside, is 180 feet from the threshold of the entrance to the back of the innermost chamber. A flight of steps leads from the river to the fore-court carved out court rises the imposing facade with its rows of graven captives, its hollow cornice and embellished balustrade. The entrance is at the center, flanked on the north and the south by pairs of colossal statues of Rameses II., the northern pair shown in the accompanying engraving. The temple proper consists of an eight-pillared, Great Hypostyle Hall, 58 feet by 54 feet, corresponding to the covered colonnades of the temples built in the open, a four-pillared Small Hypostyle Hall, 36 by 24 feet, a transverse chamber connected with the latter by three doors, and the inner sanctuary. Besides this, there are eight smaller chambers adjoining either the large or small hall, which were evidently used as storerooms for the temple utensils and furniture. The walls, the ceil. ings, and the square pillars are covered with reliefs, still vividly colored and of great historical value. They usually depict events of importance that occurred during the reign of Rameses II., but in some cases the intention of the artists appears to have been to secure decorative effects only.

Remarkable as the temple proper is, the real interest in the structure centers in the colossi of Rameses II. grouped about the entrance and hewn out of the cliff against which their backs are placed. Each of these gigantic figures, 65 feet in height, is larger than the world-famous colossi of Memnon, and despite the enormous scale on which they are executed, the workmanship is admirable. The pleasing, intelligent countenance and characteristic nose of the great Pharaoh are best preserved in the southernmost statue, though the northern pair shown in the photograph are little inferior. The second colossus has unfortunately been partially destroyed, and the head and shoulders, which have fallen from the rest of the body, lie upon the ground at its base. The supporting stonework under the cracked right arm of the first of the colossi in the photograph was placed in that position by one of the later kings of the $19 t h$.

Rameses II. is shown in the statues with the double crown of Upper and Lower Egypt. His hands rest upon his knees and from his neck depends a ring bearing his name. This is also carved upon the upper arm and between the legs. To the right and left of each colossus and in various other places are smaller figures of other members of the royal family. Upon the southern pair of statues are several Greek, Carian, and Phœnician inscriptions of considerable philological and historical interest, which were carved by soldiers of military expeditions which had penetrated as far as Abu Simbel during the centuries

It is almost impossible to describe the majesty and splendid dignity of these tremendous figures. To be truly, appreciated they must be viewed under the dazzling glare of the Egyptian sun or the brilliant whiteness of the Egyptian moon. Even the human figure standing upon the hand of the statue as shown in the photograph helps us but dimly to comprehend with what infinite toil and patience the thousands of slaves and bondsmen, laboring with their primitive tools under the sting of the taskmasters' lashes, hewed these monster human likenesses from the living granite. And even though our understanding of the methods with which they wrought and the purposes for which they raised their edifices is but too often fragmentary,

our admiration for these old Egyptian builders is boundless, and we can only regret that Time, the
stroyer, made it impossible for us to complete the stroyer,

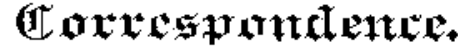

Where Did the Photographer Stand?

To the Editor of the Scientific AMERICAN:

The article in your issue of June 10, 1905, entitled "Where Was the Camera Set Up?" by Prof. William F. Rigge, has been of special interest to me.

I wish to thank the professor for his novel solution of a somewhat ifficult problem; and at the same time I take the liberty of calling his attention to the fact that his last statement appears to be somewhat erro-

Were the picture plane parallel with the front of the observatory, the mortar lines in the front of the transit room would have retained their normal position in the photograph, but as near as I can tell from the reduce cut, accompanying the article, they vanish at a point on the horizon 347 feet to the right of $\bullet$. This is the vanishing point of east-and-west lines, or $V R$. If a transit is set up at this point and traine on the optical center of the camera, the line will be found to be due east and west, or at right angles with the line from the camera to point $\bullet$. Then train the transit on $\bullet$, and the angle will be found to be very nearly $10 \mathrm{deg}$. 45 min. and the course will be N. 89 deg. 15 min. W., showing that the plate in the camera formed an angle of about 10 eg. $45 \mathrm{~min}$. with the front of the observatory, instea of about $8 \mathrm{deg}$., as stated, and the entire front of the building would measure 4 and $9 / 16$ inches instead of $4 \frac{1}{8}$ inches, as it does in the cut, showing that the lines are reduce a little more than 10 per cent. The angle of the picture plane with the front of the building also accounts for the apparent shortening of the wall space at the left of the door to the equatorial room, which, were they parallel, would show a trifle larger than that between the door and angle at the right.

Pittston, Pa., June 13, 1905 B. F. CrawFer.

The Intelligence of a Cat.

To the Editor of the Scientific American:

I have rea with much interest the letters in the Scientific A Merican describing how cats opened doors by climbing to the old-fashione thumb catch and pulling it down with their paws. In confirmation of the evident reasoning powers of cats, I want to relate to you what a cat that I owned a few years ago.

One night my wife and I were awakened by the door bell ringing. My wife got out of bed and answered the call by asking, "Who's there?" Not receiving a response, she opened the door and in bounded the cat with a "Meouw," as much as to say, "Thank you for letting me in." We could hardly credit the belief that the cat had rung the door bell, but we were conattention to it soon after by saying that she had seen our cat ring the door bell that afternoon by standing on his hind legs and with his front paws busily engaged in pulling the handle up and down until it rang.

Whenever he wanted to get in the house in the night time he would ring the bell, much to our disgust, so I thought I would lock him up in an old hen coop after supper. This worked well for a few nights, until he got wise to the fact, and then he made himself conspicuous by his absence, and all the calling I could do would not bring him in sight, although he was very much attache to me. Later on, however, after we had gotten sound asleep, the door bell would ring again and I would let him in.

I have owned a number of very smart cats, but this one exhibite greater reasoning powers than any cat I ever saw, but like the good boys and girls in story books, he died young, giving up the ghost soon after he was a year old.
Coopersville, Mich., July 5, 1905.

\section{American Homes and Gardens.}

To the Editor of the SCIENTIFIC A MERICAN:

Please accept our most sincere congratulations upon your new departure in the field of literature and maga zine publication.

A better title than "American Homes and Gardens" could never have been chosen, and the table of conbeginning to end.

The success of such an enterprise under the aus pices of the Scinntrific American is a foregone conclusion. The word "American" appeals to everyone who is inspired with love of country and patriotic pride and the word "Homes" is as broad and dear in its signification as the very globe upon which we live. "Gardens," too, conveys the true idea of what the surroundings should be, of beautiful grounds, large or small, as the case may be, which should constitute the 